\title{
An Exploratory Case Study of Transgender and Gender Nonconforming Inclusion at a Metropolitan Library in the Southeastern U.S.
}

Liz Movius, University of Tennessee, Knoxville, USA

\begin{abstract}
This article examines the existing diversity and inclusion responses to transgender and gender nonconforming patrons at a large, metropolitan public library in the southeastern U.S. Research shows that transgender and gender nonconforming individuals face unique challenges when navigating libraries. These challenges include inadequate collections, microaggressions from reference staff, a lack of gender-neutral bathrooms, and circulation policies preventing remote name changes. To compensate for these difficulties and increase accessibility for transgender and gender nonconforming patrons, libraries should incorporate diversity and inclusion initiatives into their functions. The author evaluated current collections, programs, services, policies, and resources for inclusivity, equity, and accessibility and created a strategic diversity action plan for the institution. The strategic diversity action plan identified six steps the library should take to foster inclusion and increase accessibility for its transgender and gender nonconforming patrons. These six steps include: 1) create an official, transgender-friendly bathroom policy; 2) develop a diversity and inclusion statement that includes gender identity in its language; 3 ) invest in staff training and continuing education about gender, sexuality, and transgender issues and service needs; 4) conduct a needs assessment of the transgender and gender nonconforming community; 5) establish programming based on the needs and wants expressed by the transgender and gender nonconforming community; and 6) implement a remote name-change or preferred name-change process.
\end{abstract}

Keywords: diversity; gender nonconforming; inclusion; LGBTQ+; public libraries; transgender

Publication Type: research article

\section{Introduction}

A ccess has been the perceived hallmark of public libraries in the U.S. since they were established. However, this perception does not match the true history of libraries, particularly in the southern U.S. Under Jim Crow, public libraries oppressed their own community members through racism and segregation (Weigand, 2017). Until the 1960's, African American patrons could not use the full spectrum of services offered by their public libraries (Knott, 2015). Instead, they were relegated to under-staffed and underfunded "Negro branches" where collections and resources were limited (Graham, 2002). Although libraries have evolved in the last fifty to sixty years, it is vital that awareness of past wrongs guide present decisions to prevent repeated mistakes. Today, the first tenet of the American Library Association's (ALA's) Professional Code of Ethics states: "We provide the highest level of service to all library users through appropriate and usefully organized resources; equitable service policies; equitable access [emphasis added]; and accurate, unbiased, and courteous responses to all requests" 
(2008b). Progress has been made, but this contemporary moment is tied to a problematic history. In light of challenges in their history, public libraries must be diligent in their dedication to equitable access for all patrons, regardless of race or gender identity, among other aspects.

Diversity and inclusion are the foundation upon which equitable access is built. The ALA's Strategic Plan identifies equitable access as a key action area, particularly vital for people who experience discrimination, isolation, barriers, and distress $(2017$, p. 2). Diversity and inclusion, however, do not grow without intentional cultivation. It is not enough to simply open the doors of the library with a willingness to serve those who visit and subsequently call that openness and willingness inclusion. Dali and Caidi (2017) describe this as "add-on diversity" as opposed to "diversity by design." Diversity by design places inclusion at the core of the library, integrating it seamlessly into decision making, hiring practices, collections, and public programming. Given the current sociopolitical environment in the United States, dedication to diversity and inclusion by design is of the utmost importance. On January 17, 2018, the U.S. Department of Health and Human Services began to pave the way for health professionals to discriminate against and refuse treatment to lesbian, gay, bisexual, transgender, and queer (LGBTQ+) people, citing religious freedom (Eilperin \& Cha, 2018). In light of this and other disturbing news, libraries must renew their commitment to equitable access and service, making it clear that they are dedicated to including vulnerable communities. Diversity and inclusion should not be treated as a trend, rather, they should be treated as the library's foundation; included by design, not as an addition (Cooke, 2017; Dali \& Caidi, 2017).

Transgender patrons, in particular, often report low satisfaction with library services, a lack of helpful resources, and reference interactions that range from apathetic to antagonistic (Drake \& Bielefield, 2017). Despite the measure of progress made for lesbian, gay, and bisexual (LGB) civil rights with the passage of marriage equality in 2015 (Obergefell v. Hodges), transgender and gender nonconforming (GNC) people have been left behind and, in many cases, are facing more fierce opposition. This article will examine the inclusion of transgender and GNC people at a large, metropolitan library in the southeastern U.S. Due to internal challenges with the library's marketing and communication department, the library will remain anonymous and therefore is referred to as Library $\mathrm{X}$, however, the findings reported in this article will be communicated to the collaborating staff at the agency.

Although attempts to pass a transphobic bathroom bill in the state in which Library $\mathrm{X}$ is located failed in 2017 and again in early 2018, transgender and GNC individuals still experience higher rates of poverty, homelessness, and harassment than their cisgender LGB and cisgender heterosexual peers, in addition to anxiety caused by the continual threats from the state legislature (Bado, 2017; James et al., 2016; Sisk, 2018). Furthermore, according to the ALA Library Bill of Rights, librarians have a professional obligation to provide patrons equal access and service, regardless of their gender identity (ALA, 2008a). Although service to transgender patrons may be challenged by the current government administration, if libraries in conservative communities make their services to specific populations part of a larger, systemic focus on equitable access, then the challenges posed by antagonistic forces can be minimized (Cooke, 2017). Whether or not the local government supports them, it is vital that libraries find ways to show transgender and GNC patrons that they are valued community members.

\section{Community Context}

City $\mathrm{X}$ is the capital and the largest city in its state, with an estimated population of over 684,000 (Davis, 2017). ${ }^{1}$ It is also part of the largest metropolitan area in its state; the thirteen counties

The International Journal of Information, Diversity, \& Inclusion, 2(4), 2018

ISSN 2574-3430, publish.lib.umd.edu/IJIDI/ 
that make up the greater City $X$ metropolitan area have an estimated total population of 1.8 million (United States Census Bureau, 2016). City X is well known for its history of dedication to the arts and education and has a strong, rapidly growing business and industry presence (Strauss, 2017). Out of the four most populous cities in the state, City $X$ has the highest score on the Human Rights Campaign's (HRC's) Municipal Equality Index (MEI), with a score of 60 out of 100 (redacted for anonymity). The MEl is a tool used to rank cities based on their friendliness and protections for LGBTQ+ people (HRC, 2017). According to a local LGBTQ+ magazine, City $X$ is considered a "Best Place to Live" for LGBTQ+ people in the southern U.S. and has a strong LGBTQ+ presence (Grady, 2017).

The Metropolitan Government of City X (also referred to as Metro), the third largest employer of city residents as of June 30, 2017 (Metro, 2017a, p. H-33), operates under a nondiscriminatory policy that includes sexual orientation and gender identity in its protections (Metro, n.d.). When the city attempted to expand the nondiscrimination ordinance to cover contractors as well as employees, however, the state legislature struck the ordinance down (Fenton, 2011). In spite of the state's interference, Metro still honors the nondiscrimination ordinance (Metro, n.d.). It must be noted that the state prohibits cities from passing nondiscrimination laws, meaning that Metro's nondiscrimination ordinance is a policy without the force of law behind it. This offers Metro employees a limited measure of protection for only as long as Metro chooses to abide by the policy. Due to a conservative state government, this is the most Metro can offer (Movement Advancement Project, 2018). This relative LGBTQ+-friendliness notwithstanding, there are still areas of LGBTQ+ inclusivity in the city that need improvement. For instance, the health insurance that Metro offers to its employees does not cover transgender-related healthcare, such as hormones, surgery, and other specialized care. There are also no city services provided to the LGBTQ+ community (HRC, 2017b).

The south is home to $35 \%$ of the LGBTQ+ population of the U.S., more than any other region. Although support for LGBTQ+ people has, on average, been steadily increasing in this region in the last ten years, they are still more likely to lack health insurance, employment protections, and to have difficulty affording food and healthcare than in other regions (Williams Institute, 2016b). The legal and economic disadvantages faced by LGBTQ+ people in the south are exemplified by the actions of the state legislature of City $X$. The legislature has gone to great lengths to keep LGBTQ+ residents, particularly those who are transgender and GNC, from receiving legal protections and inclusion. The state Human Rights Commission specifically delineates in the state Human Rights and Disabilities Act that the purpose of the code is to "safeguard all individuals within the state from discrimination because of race, creed, color, religion, sex, age or national origin in connection with employment and public accommodations" (p. 1). However, it makes certain to explicitly state, "“sex" means and refers only to the designation of an individual person as male or female as indicated on the individual's birth certificate" (p. 3). Additionally, the state prohibits residents from changing sex designation on their birth certificate (NCTE, 2018). These laws and the state's restriction against nondiscrimination laws have serious implications, from transgender and GNC citizens' voting rights, to healthcare, and to employment.

By 2040 , the population of City $X$ is projected to exceed 800,000 . Consequently, Library $X$ has implemented a Strategic Plan and a Facilities Master Plan designed to keep the library relevant in a quickly-growing city. Currently, the Library $X$ system has over twenty locations in City $X$ and employs nearly 400 people (Library X, n.d.e; Metro, 2017b). The plans identify underserved areas of the city and propose improvements, renovations, and new construction based on four quadrants of the city and the communities living there. The Strategic Plan focuses on five basic

The International Journal of Information, Diversity, \& Inclusion, 2(4), 2018 ISSN 2574-3430, publish.lib.umd.edu/IJIDI/ 
areas: community engagement, literacy, equitable access, fostering a culture of excellence, and resource leveraging (Library X, 2017b) in order to fulfill Library X's mission (Library X, n.d.a). The Strategic Plan also lists the library's vision and values. The vision, paraphrased to preserve anonymity, is to enrich and empower the lives of all members of the library's diverse community through unlimited learning opportunities. The values include extraordinary customer service, love of reading, lifelong learning, intellectual freedom, innovation, excellence, and inclusiveness (Library X, 2017b). There are also two objectives listed in the Strategic Plan that explicitly include diversity in their language. The first is to advance diversity and inclusion within Library $X$ 's staff and city. And, the second is to recognize changing demographics and align services for equitable access (Library X, 2017b).

Based on their Strategic Plan, it seems that Library $\mathrm{X}$ places a high priority on inclusion, as demonstrated in their vision, values, and goals. To the extent that strategic plans are indications of intent, it appears that the Library X system's success is linked to their dedication and action with respect to those goals. They offer a variety of programs and services to people of all backgrounds, reflecting an apparent belief that books represent only one of the many ways a library serves its communities (Library X, 2015).

According to the U.S. Census Bureau (USCB) (2016), City X is $56.4 \%$ white, not Hispanic or Latinx; $10.1 \%$ Hispanic or Latinx; 3.7\% Asian; $0.5 \%$ Native American; and 28.1\% black or African-American. The percentages for these racial/ethnic groups in the whole U.S. are $61.3 \%, 17.8 \%, 5.7 \%, 1.3 \%$, and $13.3 \%$, respectively (USCB, 2016). City X is also home to almost 36,000 veterans, out of a total population of 684,000 . Within City $X, 51.8 \%$ of residents are female; $87 \%$ graduated high school; $8.5 \%$ have a disability; and $17.1 \%$ live below the poverty line, compared to a national average of $12.7 \%$ (USCB, 2016). Information about LGBTQ+ people is not included in the census, however the Williams Institute of UCLA estimates that $2.8 \%$ of the population of the state in which City $X$ is located identify as LGBTQ+, which is the equivalent of roughly 19,000 people in City X (Williams Institute, 2016a). Given City X's reputation within their state as a safer city for LGBTQ+ residents, it is possible that the actual number of LGBTQ+ people living in City X may be higher than estimated.

\section{Strategic Diversity Manifesto: A Brief Analysis}

This assessment of diversity and inclusion initiatives at Library $X$ draws on the Strategic Diversity Manifesto (SDM) by Mehra \& Davis (2015) for its framework of application to identify various information responses provided for transgender and GNC patrons at the agency. The SDM evaluates information organizations according to three components: who, what, and how. The "who" component identifies and describes library users "in terms of their psychological, behavioral, and demographic attributes as contextualized in response to localized environments" (Mehra \& Davis, 2015, p. 19). The "what" component identifies information and resources offered by the organization. These resources are further broken down into three categories: information sources, information policy and planning, and connections. The "how" component connects the "who" and the "what" components by providing examples of organizational resources directed at different target groups.

\section{Methodology}

Library X's diversity initiatives were analyzed using the SDM as a framework to examine "who," "what," and "how" components. The "who" components include three levels: general diversity, 
LGBQ+, and transgender/GNC people. These levels examine Library X's diversity and inclusion initiatives from the multifaceted view of general diversity to the focused view of explicitly transgender and GNC inclusion. Each of the "what" components of information sources, information policy and planning, and connections, are evaluated with respect to the three "who" component levels and subsequent examples are described in the "how" component.

The examination of Library X's available materials involved content analysis of various documents to identify concepts pertaining to diverse communities and the relationships between the library, the concepts, and the communities. The author analyzed Library X's website, catalog, and internal policies using this method, with respect to information sources, information policy and planning, and connections. To examine information sources, the author conducted three rounds of catalog searches. First, to determine the level of transgender and GNC inclusion in the catalog, the author executed Search A using the keywords transgender, gender nonconforming, gender minority, transsexual, and nonbinary. (NB: transsexual is an archaic term for transgender that is no longer used by the trans community, however it was included in this search because it is still used by the Library of Congress (LOC) in their Demographic Group Terms classification (2017), and therefore may still appear in cataloging). Second, to determine the level of broader LGBTQ+ inclusion in the catalog, the author conducted Search B using the additional keywords lesbian, gay, bisexual, asexual, pansexual, sexual minority, queer, LGBT, and LGBTQ. Third, to determine the levels of inclusion for other diverse groups in the catalog, the author executed Search C1, $\mathrm{C} 2$, and $\mathrm{C} 3$ to gather resources related to race and ethnicity, people with disabilities, and people experiencing poverty and homelessness, respectively. While the number of additional diverse identities is necessarily limited by the scope of the present study, the author selected these three aspects of diversity to help provide a well-rounded assessment of Library X's collections. The keywords used for Search C1 were race, ethnicity, African American, Latinx/o/a, Hispanic, Asian American, and Native American. The keywords for Search C2 were disabilities, chronic illness, mental illness, and Americans with Disabilities Act. The keywords for Search C3 were homelessness, poverty, and low income.

\section{Diversity Responses at Library X}

The information sources category is divided into two subcategories: collections and noncollection resources (e.g. databases, libguides, reading lists). Catalog Search A returned the following results: 195 books, 124 ebooks, 53 audiobooks, and 46 films. Catalog Search B returned 2,184 books, 1,494 ebooks, 610 audiobooks, 1,040 music items, and 596 films. Catalog Searches $\mathrm{C} 1, \mathrm{C2}$, and C3 returned 20,473 books, 10,622 ebooks, 4,993 audiobooks, 3,079 music items, and 3,674 films total. Based on the existence of these items in the collection, the author believes Library $\mathrm{X}$ is partially successful in regard to its inclusion of transgender/GNC, LGBQ+, and broader diverse people in its collections. However, a rigorous content analysis of these items must be conducted in the future to develop a more comprehensive assessment and to address common problems pertaining to relevance versus recall. Such an analysis would evaluate items for age, relevance, discriminatory or oppressive rhetoric, as well as refining search terms, such as removing items using "gay" to refer to happy and including archaic terminology such as "homosexuals" and "hermaphrodites," both of which are still in use by the Library of Congress standards (2017).

An analysis of Library X's non-collection resources revealed that none are targeted to transgender or GNC people and their needs. Nor were there any databases targeted to LGBQ+ people (Library $X$, n.d.c). These resources, such as LGBT Life by EBSCO, are offered by some other large,

The International Journal of Information, Diversity, \& Inclusion, 2(4), 2018

ISSN 2574-3430, publish.lib.umd.edu/IJIDI/ 
metropolitan public library systems in the southern U.S. and have been reviewed by Library Journal (EBSCO, n.d.). Although Library X lacks coverage in these areas, they do have two health databases with pertinent topics: Gale Health \& Wellness Resource Center and Rosen Teen Health \& Wellness. Gale Health \& Wellness Resource Center collects academic journal articles, news articles, and other reputable resources and curates them by topic for users to browse. Included in the listed topics are gender dysphoria, intersex states, hormone replacement therapy, and sex reassignment surgery, all of which are relevant to the transgender and GNC community (Gale, n.d.). The Rosen Teen Health \& Wellness database has a specific section for sexuality and sexual health with a sexual identity subsection that contains information about sexual orientation, gender identity, and gender dysphoria, among other related topics. Although there is no information about transitioning or how to transition, there are citations at the bottom of every page that teens could use to locate further information, if necessary (Rosen Digital, n.d.). So, even though these databases are not exclusive to transgender, GNC, or LGBQ+ patrons, these patrons may still find them useful. Finally, in the realm of broader diversity, there are various educational databases available to library patrons who speak Spanish (Library X, n.d.c). Table 1 summarizes Library X's existing diversity and inclusion efforts regarding information sources.

Table 1. Library X's specific diversity and inclusion efforts with respect to information sources

\begin{tabular}{lll}
\hline Information Sources & Whow & \\
\hline What & Transgender/GNC & $\begin{array}{l}\text { Various items related to } \\
\text { transgender/GNC issues and people were } \\
\text { available in the online catalog } \\
\text { Various items related to LGBTQ+ issues } \\
\text { and people were available in the online } \\
\text { catalog }\end{array}$ \\
& General & $\begin{array}{l}\text { Various items related to issues of } \\
\text { diversity, inclusion, and equity were } \\
\text { available in the online catalog }\end{array}$ \\
& Transgender/GNC & None \\
Non-collection & LGBQ+ & None \\
Resources & General & $\begin{array}{l}\text { Various educational databases are } \\
\text { available in Spanish with a library card; } \\
\text { collection and research information } \\
\text { regarding the racial and ethnic diversity } \\
\text { in the Special Collections department is } \\
\text { also available }\end{array}$ \\
& &
\end{tabular}

The information policy and planning category is also divided into two subcategories: diversity committee and diversity representation. The diversity committee at Library $X$ describes its mission as examining community needs in areas related to equity, diversity, and inclusion and 
making recommendations for actions regarding accessibility, hospitality, awareness, and training throughout the library system and its policies and programs. The committee includes explicit references to ethnicity, gender, age, national origin, status, disability, sexual orientation, education, religion and economic status, but lacks language that encompasses gender identity, leaving out transgender and GNC people (Library X, 2017a). Furthermore, this information, including the names of the committee members, is available only on Library X's internal, employee intranet and inaccessible to the public, which limits its effectiveness.

Diversity representation, on the other hand, encompasses diversity statements and explicit inclusion of diversity in the agency's strategic plan. While Library X does not have a specific diversity statement, it does include explicit diversity-related language in its strategic plan. For example, Library X's vision, as described in its strategic plan, is to enrich and empower the lives of all members of the library's diverse community through unlimited learning opportunities. Additionally, one of the seven organizational values enumerated in the strategic plan is inclusivity. Finally, two of the twenty-two organizational objectives set forth in the strategic plan are related to diversity. The first is to advance diversity and inclusion within Library X's staff and city. The second is to stay attuned to changing demographics and align services for equitable access (Library X, 2017b). Although the diversity representation in Library X's strategic plan does not reference specific demographics, such as transgender, GNC, or LGBQ+ people, it does contain broader diversity-related language that is encompassing of many identities and backgrounds. Table 2 summarizes Library X's existing diversity and inclusion efforts regarding information policy and planning.

The connections category is divided into three subcategories: centers and organizations, community engagement, and news and events. There are no centers, organizations, or agencies within Library X dedicated to transgender, GNC, or LGBQ+ issues. Nor are there currently any community partnerships, outreach programs, or marketing to these groups. However, connections for other diverse groups do exist at Library X. The special collections department has a whole room and an organization dedicated to the history of African Americans in City $X$ (Library X, n.d.g). Library X also partners with a variety of community organizations in service of diverse groups. These partnerships include U.S. Citizenship and Immigration Services to provide programs for new Americans; Metropolitan Government of City X to connect homeless patrons with housing, welfare, and mental health opportunities; and Veterans' Affairs to connect homeless and struggling veterans with services they need (Library X, n.d.d; Library X, n.d.f). Additionally, Library $X$ has a department dedicated to equitable access for people with disabilities, including, among others, people with reading disabilities, with visual impairments, with autism, and for the deaf and hard of hearing (Library X, n.d.b). Table 3 summarizes Library $X$ 's existing diversity and inclusion efforts regarding connections.

\section{Discussion}

Library X's diversity performance overall, including the relationships between the "who," "what," and "how" components of the SDM, is described in Table 4. Collection resources exist for transgender and GNC patrons, as well as LGBQ+ patrons and other diverse communities. However, transgender and GNC patrons are not represented in any additional "what" component areas, resulting in a score of 1 out of 7 for Library $X$ with regards to transgender and GNC inclusion. $\mathrm{LGBQ}+$ patrons are included in the scope of the diversity committee, so Library $X$ received a 2 out of 7 score for LGBQ+ inclusion. Based on these results, the author created a strategic diversity action plan for Library $X$.

The International Journal of Information, Diversity, \& Inclusion, 2(4), 2018

ISSN 2574-3430, publish.lib.umd.edu/IJIDI/ 
Table 2. Library X's existing diversity and inclusion efforts regarding information policy and planning

\begin{tabular}{lll}
\hline Information Policy and Planning & \\
\hline What & Who & How \\
\hline $\begin{array}{l}\text { Diversity } \\
\text { Committee }\end{array}$ & Transgender/GNC & $\begin{array}{l}\text { A diversity committee exists, but does } \\
\text { not include gender identity in its mission }\end{array}$ \\
& LGBQ+ & $\begin{array}{l}\text { A diversity committee exists and includes } \\
\text { sexual orientation in its mission }\end{array}$ \\
& General & $\begin{array}{l}\text { A diversity committee exists and includes } \\
\text { a broad range of identities in its mission }\end{array}$ \\
Diversity & Transgender/GNC & $\begin{array}{l}\text { Strategic plan includes general language } \\
\text { about diversity, but no reference to } \\
\text { specific demographics }\end{array}$ \\
& LGBQ+ & $\begin{array}{l}\text { Strategic plan includes general language } \\
\text { about diversity, but no reference to } \\
\text { specific demographics }\end{array}$ \\
& General & $\begin{array}{l}\text { Strategic plan includes general language } \\
\text { about diversity, but no reference to } \\
\text { specific demographics }\end{array}$ \\
\hline
\end{tabular}

Table 3. Library X's specific diversity and inclusion efforts with respect to internal and external connections

\begin{tabular}{lll}
\hline Connections & & \\
\hline What & Who & How \\
\hline $\begin{array}{l}\text { Internal } \\
\text { Centers and }\end{array}$ & Transgender/GNC & None \\
Organizations & LGBQ+ & None \\
& General & The Special Collections department has \\
& & an organization dedicated to the history \\
& & of African Americans in City X \\
External & Transgender/GNC & None \\
Community & LGBQ+ & None \\
\hline
\end{tabular}




\begin{tabular}{|c|c|c|}
\hline Engagement & General & $\begin{array}{l}\text { Library X partners with U.S. Citizenship } \\
\text { and Immigration Services to provide a } \\
\text { program that guides immigrants through } \\
\text { the citizenship process; there are also } \\
\text { partnerships that target homeless } \\
\text { patrons, including job and housing } \\
\text { assistance and mental health support; } \\
\text { and partnerships with Veterans' Affairs }\end{array}$ \\
\hline \multirow[t]{3}{*}{ News and Events } & Transgender/GNC & None \\
\hline & LGBQ+ & None \\
\hline & General & $\begin{array}{l}\text { In addition to the programs described } \\
\text { above, Library } X \text { has a division dedicated } \\
\text { to equal access that provides services for } \\
\text { patrons who are blind, deaf, or need } \\
\text { other ADA accommodations }\end{array}$ \\
\hline
\end{tabular}

Table 4. Library X's overall diversity response performance.

\begin{tabular}{|c|c|c|c|c|c|}
\hline What & How & Who & & & \\
\hline & & $\begin{array}{l}\text { Transgen } \\
\text { der/GNC }\end{array}$ & LGBTQ+ & General & Total \\
\hline \multirow[t]{2}{*}{$\begin{array}{l}\text { A. } \\
\text { Information } \\
\text { Sources }\end{array}$} & $\begin{array}{l}\text { A1. Collections, such as print } \\
\text { and electronic, monographs and } \\
\text { periodicals, web portals and } \\
\text { online and physical exhibits }\end{array}$ & Y & $\mathrm{Y}$ & $\mathrm{Y}$ & $3 / 3$ \\
\hline & $\begin{array}{l}\text { A2. Resources, such as } \\
\text { databases and print indexes, } \\
\text { research guides, staff } \\
\text { (reference, instruction, etc.) }\end{array}$ & $\mathrm{N}$ & $\mathrm{N}$ & $\mathrm{Y}$ & $1 / 3$ \\
\hline \multirow[t]{2}{*}{$\begin{array}{l}\text { B. } \\
\text { Information } \\
\text { Policy and } \\
\text { Planning }\end{array}$} & $\begin{array}{l}\text { B1. Diversity committee, } \\
\text { including identification of } \\
\text { committee members' contact } \\
\text { information }\end{array}$ & $\mathrm{N}$ & $\mathrm{Y}$ & $\mathrm{Y}$ & $2 / 3$ \\
\hline & $\begin{array}{l}\text { B2. Diversity representation, } \\
\text { such as a diversity statement, } \\
\text { inclusion in strategic plan, etc. }\end{array}$ & $\mathrm{N}$ & $\mathrm{N}$ & Y & $1 / 3$ \\
\hline C. & C1. Centers and organizations, & $\mathrm{N}$ & $\mathrm{N}$ & $\mathrm{Y}$ & $1 / 3$ \\
\hline
\end{tabular}




\begin{tabular}{|c|c|c|c|c|c|}
\hline \multirow[t]{4}{*}{$\begin{array}{l}\text { Connections, } \\
\text { Internal and } \\
\text { External }\end{array}$} & \multicolumn{5}{|l|}{$\begin{array}{l}\text { departments and offices, } \\
\text { including physical and/or } \\
\text { intellectual access to internal } \\
\text { agencies and units in the library }\end{array}$} \\
\hline & $\begin{array}{l}\text { C2. Community engagement, } \\
\text { such as connections to external } \\
\text { community-based diversity } \\
\text { agencies }\end{array}$ & $\mathrm{N}$ & $N$ & $Y$ & $1 / 3$ \\
\hline & $\begin{array}{l}\text { C3. News and upcoming events } \\
\text { (within the past one year), } \\
\text { including information on } \\
\text { internal/external activities and } \\
\text { events }\end{array}$ & $N$ & $N$ & $Y$ & $1 / 3$ \\
\hline & & $1 / 7$ & $2 / 7$ & $7 / 7$ & $10 / 21$ \\
\hline
\end{tabular}

\section{Strategic Action Plan for Library X}

The strategic diversity action plan for Library $X$ is comprised of six goals. They are:

1. Create an official, transgender-friendly bathroom policy.

2. Create a diversity and inclusion statement that includes gender identity in its language.

3. Invest in staff training and continuing education about gender identity, sexuality, and transgender issues and service needs.

4. Conduct a needs assessment of the transgender and GNC community.

5. Establish programming based on the needs and wants expressed by the transgender and GNC community.

6. Implement a remote name, or preferred name, change process.

\section{Create an Official, Transgender-Friendly Bathroom Policy}

Using the bathroom can be a harrowing experience for people who are transgender or GNC. The decision to use a public bathroom opens transgender and GNC people to harassment, violence, and public shame (James et al., 2016). As a result, a vital part of making the library welcoming to transgender and GNC people is having an official policy allowing patrons to use the bathroom in which they feel most comfortable. Additionally, members of the transgender and GNC community who identify as nonbinary or gender neutral may feel uncomfortable choosing between "men" and "women," so having single-stall, gender-neutral bathrooms as part of the 
policy would make the library more welcoming to them as well (NCTE, 2016, July 10).

\section{Create a Diversity and Inclusion Statement that Includes Gender Identity in its Language}

The Equity, Diversity, and Inclusion Committee at Library X was created to support the agency's goal of providing excellent service to its diverse community, however gender identity is not included in the language describing the scope of that committee. Additionally, information about that committee is not publicly available. The author suggests that Library X implement a diversity statement such as:

"Library $X$ is proud to provide excellent service to our diverse community. Because of our library's and our city's commitment to diversity and inclusion, we do not discriminate on the basis of race, color, national origin, gender, gender identity, sexual orientation, age, religion, creed or disability in admission to, access to, or operations of our programs, services, or activities."

This statement is based on the non-discrimination statement of the Metropolitan Government of City $X$ (n.d.), but it is personalized for the library while emphasizing the partnership between City $X$ and Library $X$ in service of the community.

\section{Invest in Staff Training and Continuing Education about Gender Identity, Sexuality, and Transgender Issues and Service Needs}

In order for Library $X$ to provide excellent service to their transgender and GNC patrons, staff need to have the background knowledge that will give them an understanding of the experiences and needs of transgender people, as well as how to treat them with respect, empathy, and kindness. The vocabulary used to describe transgender issues, as well as dynamics within the community, and unique challenges faced by transgender and GNC people, are often barriers for people outside those communities. For instance, the difference between sex, gender, and sexual orientation are not well known, nor is the definition of cisgender, and the distinctions between these words may result in confusion and microaggressions (Curry, 2005; Drake \& Bielefield, 2017; Jardine, 2013). Furthermore, staff education would encourage an affirming work environment where transgender and GNC staff can be safely open about their identities, which also allows transgender and GNC patrons to feel more comfortable in the library (Drake \& Bielefield, 2017). Educating staff members about the challenges faced by transgender and GNC patrons, and the circumstances that impact their experiences, would empower staff at Library $X$ to provide excellent customer service to their transgender and GNC patrons.

\section{Conduct a Needs Assessment of the Transgender and GNC Community}

The best way to determine what transgender and GNC community members want from the library is to ask them (Martin \& Murdock, 2007). This can take the form of anonymous surveys, focus groups, and interviews within the library, accessing existing community groups through a gatekeeper, or connecting to the community by participating in community events (Cooke, 2017). The author suggests that Library $X$ conduct a comprehensive needs assessment of the transgender and GNC community using all three methods.

\section{Establish Programming Based on the Needs and Wants Expressed by the Transgender and GNC Community}


Using feedback collected during the needs assessment, library staff should develop programs suited to the community's needs and wants. Drake and Bielefield (2017) identify LGBQ and transgender-themed library events, artwork, and displays as three crucial ways that libraries can help transgender and GNC patrons feel welcome and safe. Furthermore, staff should stay up-todate on local and national news and events that affect transgender and GNC people and their use of the library (Curry, 2005). Transgender and GNC patrons may also use library services that correspond to their other intersecting identities. Therefore, Library $\mathrm{X}$ should make an effort to make existing collections and services welcoming to transgender patrons, while continuing to develop additional programming (Drake \& Bielefield, 2017; Jardine, 2013).

\section{Implement a Remote Name-Change or Preferred Name-Change Process}

In order for transgender or GNC patrons to change the name on their library accounts, they must do so in person, with proper documentation (Library X, 2014). This presents transgender and GNC patrons with the uncomfortable choice of either continuing to use their former name, also called a deadname, or outing themselves to circulation staff and anyone else within earshot. The creation of a remote name-change process would allow transgender and GNC patrons to safely identify their correct name. Ideally, this process should also allow patrons to identify their correct pronouns, so that library staff may provide their transgender and GNC patrons with excellent service by addressing them accordingly (Jardine, 2013). As a result, implementing a remote name-change process, or at least a remote preferred name-change process, is one of the most important steps that libraries can take to make themselves more accessible to transgender and GNC patrons (Drake \& Bielefield, 2017).

\section{Conclusion}

There are over 1.4 million transgender adults in the U.S. (NCTE, 2016, July 9) and the number of adults in the U.S. who identify as LGBTQ+ increases every year (Gates, 2017). As transgender and GNC people become more visible and involved in community life, it is vital that libraries take action to make their services and collections more accessible to them. Although these actions may be distasteful to conservative community members, it is important for libraries to support their promise of equitable access to all people with their actions. The tension between the library's responsibility to serve the community and the threat of controversy from conservative elements for fulfilling that role is challenging to navigate. The simplest answer is that fear should never prevent libraries from serving marginalized groups; however, reality is more complex and nuanced. Due to the constraints of public funding, librarians must consider how to mitigate the degree of community resistance their actions draw, particularly in the southern U.S. Despite the problematic nature of this reality, it must be acknowledged so that librarians can move forward with effective initiatives to include transgender and GNC patrons.

Movements toward equality are not always easy or straightforward; the people of City X know that well, given the history of their city. Library $X$ is already well known for its devotion to preserving the history of the city's movement towards integration and equality in its special collections department. However, the work of strengthening inclusivity is never over. The author hopes that despite the anonymity of Library $\mathrm{X}$ within this project, the library will continue its courageous legacy of inclusivity by implementing these accommodations for transgender and GNC members of the community, so that it can provide truly excellent service to yet another element of its diverse community. 


\section{Acknowledgements}

Many thanks to Dr. Bharat Mehra for their guidance and encouragement, Jen Held for their endless support, KB for his valuable insight, LEP for her enduring patience, and all the staff from Library $\mathrm{X}$ who offered their experiences, hopes, and concerns throughout this process. The author also thanks Dr. Keren Dali and the anonymous reviewers, whose patience, encouragement, and suggestions helped turn this paper into a coherent article.

\section{Endnote}

${ }^{1}$ Respecting the preferences of the partner library, the author cannot provide complete bibliographic details for several sources cited in the text because it will identify the library in question. References to these sources are cited in the text but removed from the list of references in compliance with APA guidelines.

\section{References}

American Library Association. (2017). Strategic directions. Retrieved from http://www.ala.org/aboutala/sites/ala.org.aboutala/files/content/governance/Strate gicPlan/Strategic\%20Directions\%202017_Update.pdf

American Library Association. (2008a). Access to library resources and services regardless of sex, gender identity, gender expression, or sexual orientation: An interpretation of the Library Bill of Rights. Retrieved from http://www.ala.org/advocacy/intfreedom/librarybill/interpretations/accesslgbt

American Library Association. (2008b). Code of ethics. Retrieved from http://www.ala.org/tools/ethics

Beiriger, A. \& Jackson, R. M. (2007). An assessment of the information needs of transgender communities in Portland, Oregon. Public Library Quarterly, 26(1-2), 45-60.

Cooke, N. A. (2017). Information services to diverse populations: Developing culturally competent library professionals. Santa Barbara, CA: Libraries Unlimited.

Curry, A. (2005). If I ask, will they answer?: Evaluating public library reference service to gay and lesbian youth. Reference \& User Services Quarterly, 45(1), 65-74.

Dali, K. \& Caidi, N. (2017). Diversity by design. Library Quarterly, 87(2), 88-98.

Drake, A. A. \& Bielefield, A. (2017). Equitable access: Information seeking behavior, information needs, and necessary library accommodations for transgender patrons. Library \& Information Science Research, 39(3), 160-168.

EBSCO. (n.d.). LGBT Life. Retrieved from https://www.ebsco.com/products/research- 
databases/lgbt-life/

Eilperin, J. \& Cha, A. E. (2018, January 17). New HHS civil rights division to shield health workers with moral or religious objections. Washington Post. Retrieved from https: / / www.washingtonpost.com/national/health-science/trump-administrationcreating-civil-rights-division-to-shield-health-workers-with-moral-or-religiousobjections/2018/01/17/5663d1c0-fbe2-11e7-8f662df0b94bb98a_story.html?utm_term=.a3fa8524eb41

Gale. (n.d.). Health \& wellness resource center: Topics. Retrieved from http://go.galegroup.com/ps/browseCategory?p=HWRC\&u=tel_p_plndc

Gates, G. J. (2017, January 11). In US, more adults identifying as LGBT. Gallup News. Retrieved from http://news.gallup.com/poll/201731/lgbt-identification-rises.aspx

Graham, P. T. (2002). A right to read: Segregation and civil rights in Alabama's public libraries, 1900-1965. Tuscaloosa, AL: University of Alabama Press.

Human Rights Campaign. (2017). 2017 Municipal equality index. Retrieved from http://www.hrc.org/resources/mei-2017-see-your-citys-score

James, S. E., Herman, J. L., Rankin, S., Keisling, M., Mottet, L., \& Anafi, M. (2016). The Report of the 2015 U.S. transgender survey. Washington, DC: National Center for Transgender Equality. Retrieved from https://transequality.org/sites/default/files/docs/usts/USTSFull-Report-Dec17.pdf

Jardine, F. M. (2013). Inclusive information for trans* persons. Public Library Quarterly, 32(3), 240-262.

Knott, C. (2015). Not free, not for all: Public libraries in the age of Jim Crow. Amherst, MA: University of Massachusetts Press.

Library of Congress. (2017). Demographic group terms. Retrieved from https://www.loc.gov/aba/publications/FreeLCDGT/DEMOGRAPHIC.pdf

Martin, H. J., Jr., \& Murdock, J. R. (2007). Serving lesbian, gay, bisexual, transgender, and questioning teens: A how-to-do-it manual for librarians. New York: Neal-Schuman Publishers.

Mehra, B. \& Braquet, D. (2011). Progressive LGBTQ reference: coming out in the 21st century. Reference Services Review, 39(3), 401-422.

Mehra, B. \& Davis, R. (2015). A strategic diversity manifesto for public libraries in the 21st century. New Library World, 116(1-2), 15-36.

Movement Advancement Project. (2018). Local non-discrimination ordinances. Retrieved from http://www.lgbtmap.org/equality-maps/non_discrimination_ordinances/

National Center for Transgender Equality. (2016, July 10). Transgender people and bathroom access. Retrieved from https://transequality.org/issues/resources/transgender-peopleand-bathroom-access 
National Center for Transgender Equality. (2016, July 9). Frequently asked questions about transgender people. Retrieved from https: / / transequality.org/issues/resources/frequently-asked-questions-abouttransgender-people

Obergefell v. Hodges, 576 U. S. (2015).

Pohjanen, A. M. \& Kortelainen, T. A. M. (2016). Transgender information behavior. Journal of Documentation, 72(1), 172-190.

Rosen Digital. (n.d.). Teen health \& wellness. Retrieved from www.teenhealthandwellness.com

Strauss, K. (2017, August 9). The 10 big US cities with the fastest growing economies. Forbes. https://www.forbes.com/sites/karstenstrauss/2017/08/09/the-10-big-u-s-cities-withthe-fastest-growing-economies/\#229a1da464d5

Sylvia Rivera Law Project. (2018). Fact sheet: Transgender \& gender nonconforming youth in school. Retrieved from https://srlp.org/resources/fact-sheet-transgender-gendernonconforming-youth-school/

Thompson, K. J. (2012). Where's the "T"?: Improving library service to community members who are transgender-identified. Journal of the University of lowa School of Library and Information Science. Retrieved from https: //ir.uiowa.edu/bsides/22

Wiegand, W. A. (2017, June 1). Desegregating libraries in the American south. American Libraries. Retrieved from https://americanlibrariesmagazine.org/2017/06/01/desegregating-libraries-americansouth/

Williams Institute. (2016a). LGBT data \& demographics. Retrieved from https://williamsinstitute.law.ucla.edu/visualization/lgbt-stats/

Williams Institute. (2016b). LGBT in the South. Retrieved from https: / / williamsinstitute.law.ucla.edu/research/census-lgbt-demographicsstudies/lgbt-in-the-south/

Liz Movius (emovius@vols.utk.edu) is a recent graduate of the University of Tennessee, Knoxville School of Information Sciences. They plan to pursue a career as a public librarian with an emphasis on outreach, diversity, inclusion, equity, and service to undervalued and underserved facets of the community. 